\title{
Е.Ю. Тройнина
}

\section{ОСНОВНЫЕ НАПРАВЛЕНИЯ ПОЛИТИКИ ПО РАЗВИТИЮ МАЛЫХ И СРЕДНИХ ПРЕДПРИЯТИЙ ТАЙВАНЯ В 2010-2016 ГГ.}

\begin{abstract}
Рассмотрены тенденции и условия развития малых и средних предприятий Тайваня в 2010-2016 гг. Анализируются основные направления поддержки развития малого и среднего бизнеса и соответствующие правительственные программы. Определяются последствия Рамочного соглашения об экономическом сотрудничестве для малых и средних предприятий острова.

Ключевые слова: Тайвань; малые и средние предприятия; инновации.
\end{abstract}

Малые и средние предприятия (МСП) являются чрезвычайно важной частью экономической системы Тайваня. В соответствии с Критериями определения малых и средних предприятий Тайваня с поправками от 30 марта 2015 г. малым или средним может считаться предприятие, прошедшее необходимую процедуру регистрации, предусмотренную требованиями закона, которое отвечает следующим критериям:

1. Предприятие осуществляет свою деятельность в производственной, строительной или горнодобывающей отраслях экономики, а оплаченная часть акционерного капитала не превышает 80 млн новых тайваньских долларов (НТД) или штат постоянных сотрудников предприятия не превышает 200 человек.

2. Для прочих отраслей малым или средним считается предприятие, ежегодные объемы продаж которого составили не более 100 млн НТД или штат постоянных сотрудников не превышает 100 человек.

Микропредприятиями считаются компании, в которых работает не более 5 постоянных сотрудников [1].

Исходя из данного определения малых и средних предприятий, в 2014 г. численность МСП на Тайване составила 1353 049, или 97,61\% от общего числа предприятий [2. С. 43]. На фоне достаточно устойчивых темпов прироста экономики острова в 2010-2014 гг. за этот период число МСП увеличилось на 105 051, в относительном выражении - на 0,07\%. В 2014 г. МСП на Тайване обеспечили трудоустройство для 78,25\% всего работающего населения, что на $0,19 \%$ выше, чем в 2010 г. Отраслевое распределение МСП Тайваня в 2014 г. представлено в табл. 1.

Несмотря на то, что только $10,48 \%$ от общего числа МСП в 2014 г. составляли компании, работающие в производственном секторе, они обеспечили $36,52 \%$ от общего объема продаж всех МСП на острове, что говорит о высокой эффективности работы тайваньского малого и среднего производственного бизнеса. В табл. 2 представлены данные за 2010-2014 гг., которые демонстрируют, что доля производственных МСП на Тайване за последние 5 лет оставалась на уровне $10,5 \%$, а их доля в объеме продаж МСП - от 36 до $38,65 \%$. Однако с учетом акцента, который делается на развитие сектора наукоемких услуг, можно ожидать постепенного снижения доли производственных предприятий в будущем.

Достаточно серьезные отличия прослеживаются в структуре занятости по уровню образования на МСП и на крупных предприятиях (табл. 3).

В течение многих лет в опросах, проводимых правительством Тайваня, среди основных сложностей в работе малых и средних предприятий их руководители неизменно указывают кадровую проблему.

Статистические данные показывают, что удельный вес сотрудников с высшим университетским образованием на крупных предприятиях вдвое превышает этот показатель у МСП, а доля сотрудников со степенью магистра в разные годы в 4-6 раз выше у крупных предприятий. Такое распределение связано с тем, что выпускники вузов и обладатели ученых степеней видят более ясные перспективы карьерного роста и получения высокого дохода именно на крупных предприятиях; кроме того, крупные предприятия обычно воспринимаются как более стабильные возраст 75\% крупных предприятий Тайваня превышает 10 лет, для МСП этот показатель составляет менее 50\% [4].

Отраслевое распределение МСП Тайваня, 2014 г. [2. С. 25]

\begin{tabular}{|l|c|}
\hline \multicolumn{1}{|c|}{ Отрасль } & Доля предприятий \\
\hline Оптовая и розничная торговля & $49,40 \%$ \\
\hline Производство & $10,48 \%$ \\
\hline Гостиничный бизнес, общественное питание & $9,93 \%$ \\
\hline Строительство & $8,29 \%$ \\
\hline Прочие услуги & $5,83 \%$ \\
\hline Профессиональные, научные и технические услуги & $3,17 \%$ \\
\hline Прочее & $12,90 \%$ \\
\hline
\end{tabular}


Производственные МСП Тайваня, 2010-2014 гг. [2. С. 26]

\begin{tabular}{|c|c|c|c|c|c|}
\hline Доля производственных МСП & 2010 г. & 2011 г. & 2012 г. & 2013 г. & 2014 г. \\
\hline От общего числа МСП & $10,42 \%$ & $10,61 \%$ & $10,52 \%$ & $10,45 \%$ & $10,48 \%$ \\
\hline От общего объема продаж МСП & $38,03 \%$ & $38,65 \%$ & $38,44 \%$ & $35,99 \%$ & $36,52 \%$ \\
\hline
\end{tabular}

Уровень образования сотрудников предприятий Тайваня, 2013-2014 гг. [3]

\begin{tabular}{|c|c|c|c|c|}
\hline \multirow{2}{*}{ Уровень образования сотрудников } & \multicolumn{2}{|c|}{2013 г. } & \multicolumn{2}{|c|}{2014 г. } \\
\hline & МСП & Крупные предприятия & МСП & Крупные предприятия \\
\hline Неграмотные & 0,02 & Нет данных & 0,05 & Нет данных \\
\hline Самообразование & 0,02 & Нет данных & 0,01 & Нет данных \\
\hline Начальная школа & 8,24 & Нет данных & 7,69 & Нет данных \\
\hline Средняя школа & 14,6 & 7,4 & 14,42 & Нет данных \\
\hline Старшая школа & 10,02 & 5,25 & 10,36 & Нет данных \\
\hline Профессиональный колледж & 26,45 & 0,89 & 26,05 & 24,66 \\
\hline Двухгодичный колледж & 18,97 & 34,21 & 20,00 & 3,77 \\
\hline Университет & 16,85 & 31,88 & 16,36 & 35,34 \\
\hline Степень магистра & 4,38 & 20,37 & 4,57 & 36,23 \\
\hline Степень доктора & 0,44 & Нет данных & 0,49 & Нет данных \\
\hline
\end{tabular}

Т а б л и ц а 4

Расходы на исследования и разработки малых и средних предприятий в относительном и абсолютном выражении, 2009-2014 гг. [12]

\begin{tabular}{|l|c|c|c|c|c|}
\hline & 2009 г. & 2010 г. & 2011 г. & 2012 г. & 2013 г. \\
\hline Расходы МСП на НИОКР*, млн НТД & 44764 & 46759 & 43865 & 45213 & 47361 \\
\hline $\begin{array}{l}\text { Доля МСП в общем объеме расходов } \\
\text { частного сектора на НИОКР }\end{array}$ & $17,39 \%$ & $16,55 \%$ & $14,60 \%$ & $14,13 \%$ & $13,79 \%$ \\
\hline $\begin{array}{l}\text { Общий объем расходов частного сек- } \\
\text { тора на НИОКР, млн НТД }\end{array}$ & 257405 & 282546 & 300358 & 319906 & 343455 \\
\hline
\end{tabular}

* НИОКР - научно-исследовательские и опытно-конструкторские работы.

Доля МСП в общем объеме экспорта в 20132014 гг. снизилась до 14,5\% от общего объема экспорта, тогда как в 2008 г. этот показатель составлял $17,36 \%$, в 1995 г. $-50,65 \%$, а в 1982 г. $-69,68 \%$. Устойчивое снижение доли МСП в общем объеме экспорта Управление по делам малых и средних предприятий (УМСП) Министерства экономики Тайваня объясняет структурными изменениями в экономике острова: ввиду повышения конкуренции на экспортных рынках, а также усиления нового тайваньского доллара (НТД) МСП все чаще выступают как подрядчики крупных предприятий. Таким образом, участвуя в производстве экспортных товаров, МСП все реже выступают в качестве прямых экспортеров и, следовательно, не отражаются в статистике. При этом основными экспортерами среди МСП выступают производственные предприятия.

В последние несколько лет, со времени восстановления в 2010 г. национальных экономик после мирового финансового кризиса 2008-2009 гг., происходят существенные изменения в конъюнктуре развития тайваньских МСП. Среди основных изменений начиная с 2010 г. необходимо отметить замедление темпов развития мировой экономики и повышение конкуренции на мировых рынках. Для Тайваня, чья экономика имеет ярко выраженную экспортную ориентацию (в 2014 г. экспорт составил более $59 \%$ от ВВП острова [5. С. 9, 19]), снижение спроса на мировых рынках неизбежно ставит перед тайваньскими предприятиями вопрос об источниках сохранения темпов экономического роста.

Все больший вызов для МСП Тайваня составляют предприятия континентального Китая. Посредством оказания активной поддержки собственной промышленности, а также расширения каналов и масштабов сотрудничества с транснациональными корпорациями в рамках создания собственной автономной цепочки поставок, благодаря повышению технологического уровня все более продвинутые производства могут быть размещены на материке, вытесняя из сектора контрактных производств МСП острова. Кроме того, инфраструктурные проекты континентального Китая, а также амбициозные стратегии «Новый шелковый путь» и «Морской шелковый путь XXI века» призваны облегчить доступ предприятиям Китая на новые рынки, что делает задачу развития экономических связей тайваньских предприятий с зарубежными рынками еще более актуальной.

При этом положительными факторами, влияющими на экономику Тайваня в последние два года, стали низкие цены на нефть и энергоносители, «сильный» американский доллар и рост экономики США. Однако фактор дешевой нефти не является ключевым для развития тайваньской экономики, которая уже давно и широко использует энергосберегающие технологии. В то же время неизвестно, насколько долго фактор роста американской экономики сможет положительно влиять на темпы роста ВВП острова. Поэтому обстановку последних 5 лет можно скорее оценить как неблагоприятную для тайваньских МСП. Таким образом, для правительства и самих предприятий основными вопросами являются определение направлений развития МСП, выявление существующих и культивация новых конкурентных преимуществ. 
Особого внимания заслуживает тот факт, что правительство Тайваня на официальном уровне признало, что модель контрактных производств (ОЕМ), которая с 1970-х гг. обеспечивала устойчивый рост и содействовала повышению научно-технологического уровня экономики Тайваня, перестала выполнять данную функцию и, очевидно, изживает себя. В Белой книге по малым и средним предприятиям Тайваня, опубликованной в октябре 2015 г., неоднократно отмечается, что производство в рамках ОЕМ становится все менее маржинальным, следовательно, предприятиям становится жизненно необходимо повышать уникальность и конкурентоспособность своих товаров за счет научнотехнологической и сервисной составляющих, дизайна и т.д. Особенно актуальным этот вопрос становится на фоне повышения научно-технологического уровня предприятий на материке. В качестве одного из наиболее важных источников для инновационного развития Министерство экономики видит создание инновационных стартапов и микропредприятий.

Вопрос о неспособности старой модели контрактных производств обеспечить будущий экономический рост затронула Цай Инвэнь (избранная на пост президента Тайваня 16 января 2016 г.) в своей инаугурационной речи 20 мая 2016 г. [6]. По ее мнению, эта («старая») модель перестала быть двигателем экономики острова. В то же время одним из главных преимуществ тайваньской экономики наряду с выгодным приморским положением, высоким уровнем подготовки кадров Цай Инвэнь назвала динамичные малые и средние предприятия. Одним из первых шагов по реформированию экономической системы Цай запланировала повышение автономности тайваньской экономики (очевидно, имея в виду снижение зависимости от материковой части Китая - один из основных лозунгов ее предвыборной кампании) и одновременное усиление глобальных и региональных связей, их диверсификацию (в частности, «Новую южную политику» ${ }^{1}$ ).

В инаугурационной речи президент Цай также подтвердила свою приверженность программе пяти больших инновационных исследовательских планов (отраслей, 五大創新研發計畫), выдвинутой Демократической прогрессивной партией в сентябре 2015 г. в период предвыборной кампании [7]. Отрасли, развитие которых должно придать стимул для развития экономики острова, - «зеленая» энергетика, «интернет вещей» ${ }^{2}$, «умное» машиностроение, национальная оборона, биотехнологии и фармацевтика.

Кроме того, президент Цай подчеркнула, что модель экономического развития, которую будет продвигать новое правительство, будет опираться на три ключевых концепции - инновации, обеспечение занятости и справедливое распределение (общественное богатства. - E.T.).

Новая администрация Цай Инвэнь уже в мае 2016 г. объявила о запуске плана «Азиатская Кремниевая долина», который должен привести к реструктуризации экономики острова. Основными целями этого плана, рассчитанного на 2016-2023 гг. с общим бюджетом 358 млн долл. США является создание экосистемы, благоприятной для развития инновационных предприятий и стартапов, приоритетной отраслью являются технологии «интернета вещей» и разработка программных приложений. Еще одна цель - развитие прочных связей с Кремниевой долиной в Калифорнии и другими ведущими высокотехнологичными кластерами. В качестве пилотной зоны для проекта определен район Таоюаня. В рамках данного плана правительство Тайваня нацелено на создание 100 предприятий в этом кластере, которые будут включать как исследовательские центры крупных компаний, так и местные стартапы [8].

Звучное название данного плана, однако, весьма напоминает план, с которым пришел к власти в 2000 г. соратник Цай Инвэнь по Демократической прогрессивной партии, экс-президент Тайваня Чэнь Шуйбянь план создания «Зеленого Кремниевого острова», а выбор отраслей нового плана хотя и отражает новые технологические тенденции, в целом принципиально не отличается от приоритетов администрации Гоминьдана, делавшего акцент на нематериальное производство $^{3}$. Инструментарий нового плана Цай Инвэнь также не является новаторским - по сути, это проверенная стратегия создания научно-промышленного парка.

Программы стимулирования развития малого и среднего бизнеса на Тайване. Так как содействие развитию малых и средних предприятий является важным направлением экономической политики Тайваня, реализация ряда значимых программ была начата при администрации президента Ма Инцзю, а некоторые особо приоритетные программы, относящиеся к технологическому перевооружению МСП, действуют еще с конца 1990-х гг.

Для того чтобы придать малому и среднему бизнесу Тайваня новый импульс развития, руководство острова содействует активному участию МСП в правительственной программе «Четыре реформы трех отраслей» [9. С. 7-8], которая была принята еще в октябре 2012 г. и предусматривает следующие структурные трансформации в экономике Тайваня, которые тесно связаны между собой.

1. Повышение сервисной составляющей производства: вместе с продуктом покупателю должен предоставляться комплекс услуг, чтобы полностью удовлетворить его требования, за счет чего товар становится индивидуализированным, повышается лояльность клиента, а также добавленная стоимость всего продукта.

2. Повышение научно-технологического уровня оказываемых услуг: внедрение информационнокоммуникационных технологий (ИКТ) позволяет снижать себестоимость сделки, делать ее более удобной и качественной, повышать эффективность деятельности предприятия. К примеру, тайваньский ученый Хуан Жуйжун отмечает, что использование преимуществ, связанных с информационными технологиями - сбор 
или, наоборот, распространение информации через Интернет - может нивелировать недостатки, связанные с размером предприятия. Интернет предоставляет и малым, и крупным предприятиям практически равные возможности по сбору важной для бизнеса информации, продвижению и продаже своего продукта или услуги. Таким образом, тайваньским предприятиям необходимо более широко использовать данный канал для своего развития [10. С. 148].

Чтобы стимулировать МСП более эффективно применять информационно-коммуникационные технологии, с 2012 г. началась реализация Плана по внедрению информационно-коммуникационных инноваций для МСП. Данный план нацелен на повышение инновационных возможностей МСП благодаря интеграции «умных» технологий, создающих добавленную стоимость, и мерам по укреплению сетевых связей между МСП, усилению кластерного эффекта. В 2014 г. в рамках данного плана 77 МСП внедрили новые ИКТ-инструменты, благодаря чему, по данным УМСП, выручка этих предприятий выросла на 94 млн НТД [2. С. 165].

Примечательно, что этот план качественно отличается от предыдущих программ, связанных с внедрением ИКТ - в 2000-х гг. проводилась политика по сокращению «цифрового разрыва» между городом и сельской местностью, а также между новыми и традиционными отраслями. Отличие данного плана заключается в поддержке наиболее перспективных продуктов, услуг и целых кластеров для максимизации добавленной стоимости и последующего «подтягивания» других предприятий отрасли.

3. Интернационализация услуг: расширение охвата услугами посредством электронной торговли и интернет-банкинга, экспорта услуг (например, привлечение зарубежных туристов на Тайвань), создания за рубежом торговых представительств и сервисных подразделений, выезда местных специалистов за рубеж для оказания услуг. Если говорить, например, о показателях вовлеченности в электронную торговлю, малые предприятия заметно отстают от средних и еще сильнее от крупных $(9,82 \%, 14,55 \%$ и $17,00 \%$ соответственно в 2013 г.). В настоящее время Министерство экономики Тайваня реализует Программу по продвижению международной электронной торговли МСП, нацеленную на расширение возможностей для МСП участвовать в международной электронной торговле (например, посредством торговых интернет-площадок), подготовку кадров в области интернет-маркетинга и разработку соответствующих продуктов. В 2014 г. 109 МСП получили поддержку по данной программе и, благодаря освоению экспортных рынков, увеличили объем продаж на 670 млн НТД [Там же. С. 164].

В 2015 г. Тайвань совместно с Филиппинами начал реализацию инициативы по развитию онлайн-продаж для онлайн- и офлайн-клиентов $(\mathrm{O} 2 \mathrm{O})$ в рамках рабочей группы по малым и средним предприятиям Форума АТЭС. Целью данной инициативы является повышение конкурентоспособности МСП в области цифровых технологий и интернет-продаж посредством сотрудничества объединений МСП и подготовки специалистов в области О2О продаж [11]. В 2016 г. Тайвань объявил, что при реализации данной инициативы приоритетными будут 5 инновационных отраслей, упомянутых в инаугурационной речи Цай Инвэнь.

Следует иметь в виду, что электронная торговля совершила настоящую революцию на мировых рынках, сделав товары и услуги самого широкого спектра как никогда доступными для потребителей во всем мире, и в то же время повлекла усиление глобальной конкуренции, в которой все большую роль играет сервис, даже если речь идет о продаже осязаемого товара. Так или иначе, не участвуя в электронной торговле, предприятие лишает себя ощутимого канала сбыта.

4. Повышение специфичности продуктов традиционных отраслей: повышение добавленной стоимости и уникальности товаров и услуг за счет научнотехнологической, эстетической составляющих, использования информационно-коммуникационных технологий, инноваций, развития брендов. Однако, если рассматривать инвестиции в научно-технологическую составляющую, то в 2012-2014 г. лишь около 14\% [2. C. 44-45] от общего объема расходов корпоративного сектора на исследования и разработки составили расходы малых и средних предприятий по сравнению с 17,39\% в 2009 г. Данный показатель в 2009-2013 гг. оставался примерно на одном уровне в абсолютном выражении; существенный рост можно наблюдать в 2014 г., но ввиду отсутствия данных о последующих годах говорить о развороте тенденции пока что преждевременно. Тем не менее очевидно, что общий прирост расходов на исследования и разработки на Тайване (44,9\% за 2009-2014 гг.) происходил преимущественно за счет крупных предприятий (см. табл. 4).

В рамках программы «Четыре реформы трех отраслей» правительством Гоминьдана были выбраны 5 отраслей, в которых результаты перечисленных выше четырех типов структурных трансформаций должны проявится наиболее быстро и ярко [9. С. 10]:

1. Умная среда проживания (сервисное производство).

2. Производство автоматических станков (сервисное производство).

3. Логистика (высокотехнологичные услуги).

4. Телекоммуникационные услуги (интернационализация услуг).

5. Инновационный текстиль (традиционная отрасль, в которой должна быть повышена степень специфичности продукта).

Подобный акцент на услуги и повышение постиндустриальной составляющей экономики острова связан со стремлением преодолеть противоречие между необходимостью обеспечения экономического роста, дефицитом земельных ресурсов, которые можно выделить под производственные площади, и стремлением ре- 
шить экологическое проблемы, поскольку расширение существующих научных и промышленных парков и создание новых производственных объектов наталкивается на активное противодействие со стороны фермеров, сторонников защиты окружающей среды и части общественности. В качестве компромиссного решения правительством Гоминьдана (в настоящий момент уже передавшим полномочия Демократической прогрессивной партии, которая продолжает данный курс) было предложено развивать нематериальное производство. Эта стратегия в целом соответствует поставленным целям и имеющимся ресурсам Тайваня: развитие сектора услуг такого рода привлекает большое число квалифицированных специалистов, не требует много природных ресурсов, больших площадей, при этом создает высокую добавленную стоимость, позволяет вовлечь широкий пласт малых и средних предприятий, не загрязняет окружающую среду.

В сфере поддержки инноваций на Тайване уже более 15 лет осуществляется целый комплекс программ для малых и средних предприятий. Для того чтобы стимулировать увеличение инвестиций в НИОКР со стороны МСП, Министерством экономики в 2010-е гг. реализовывался ряд целевых программ, включающих финансовую и техническую поддержку предприятий.

1. Проект по улучшению рабочей среды для малых и средних предприятий. Задачами данного проекта являются оказание технической поддержки по вопросам улучшения рабочей среды, внедрению систем управления рисками для предприятий, консультации по вопросам безопасности и охраны здоровья, предоставление информации о содержании данной политики.

2. Программа непрерывного технического содействия малым и средним предприятиям (осуществляется с 2009 г.) предполагает оказание поддержки малым и средним предприятиям по вопросам технологической модернизации с использованием опыта и знаний корпоративного сектора и академических кругов. В 2012 г. 753 из 2290 подавших заявки МСП получили субсидии на сумму 111 млн НТД [13. С. 185]. В 2014 г. акцент был сделан на консультационную поддержку - в течение года консультации получили 323 МСП [2. С. 171].

3. Программа консультирования по вопросам промышленной модернизации и инновационных платформ (появилась в 2015 г. в результате объединения смежных программ) была запущена для поддержки исследований и разработок лидирующих компаний и их новых наукоемких товаров и услуг, имеющих хорошие перспективы освоения рынка. В 2014 г. по данной программе было одобрено 43 заявки, а объем субсидий составил 843 млн НТД [Там же. С. 172].

4. Программа инновационных исследований малого бизнеса предназначена для поддержки инновационного развития малых предприятий, их участия в инновационной деятельности в форме частичного субсидирования расходов на НИОКР (реализуется с 1999 г.). С 2008 г. право на выделение средств по данной программе по- лучили местные органы власти (муниципальные, уездные), чтобы лучше отвечать потребностям каждого региона. Ее целью является снижение расходов и рисков, связанных с исследованиями и разработками, и, следовательно, стимулирование расширения инновационной деятельности (программа рассчитана на поддержку как инновационных технологий, так и инновационных услуг). Правительственная субсидия по программе может покрывать до $30 \%$ расходов на НИОКР. С 1999 г. по май 2015 г. 5785 проектов МСП получили поддержку от Министерства экономики по данной программе, общий объем субсидий составил 10,4 млрд НТД, при этом МСП инвестировали 19,9 млрд НТД [Там же. С. 173]. Параллельно с национальной программой на тот же момент времени местные органы власти Тайваня распределили 636 млн НТД среди 2647 МСП в рамках региональной части этой программы. Это одна из наиболее крупных и важных программ по технологической модернизации малого бизнеса острова.

5. Программа развития промышленных технологий осуществлялась с 1999 по 2014 г. В рамках программы государство оплачивало часть расходов предприятий на разработку и внедрение промышленных технологий и инноваций. Результаты НИОКР, полученные с помощью этой программы, переходили в собственность предприятия, кроме того, правительство оказывало помощь в инновационном менеджменте, кадровой политике и сотрудничестве с университетами, исследовательскими институтами и другими предприятиями. В последние годы акцент был сделан на исследовательские программы, выявляющие и развивающие технологии будущего (так называемый форсайт), интегрированные НИОКР (создание инновационных экосистем, кластеров) и привлечение иностранных партнеров с целью открытия исследовательских центров на Тайване. С 1999 по 2014 г. по данной программе было одобрено 1079 заявок (планов развития промышленных технологий), по которым финансовую помощь получили 1678 предприятий. Объем субсидий составил 53,1 млрд НТД [Там же. С. 173].

6. Программа технологического развития традиционных отраслей, реализация которой была начата в 2001 г., прошла некоторую трансформацию за последние 15 лет. Изначально она была ориентирована на содействие компаниям, работающим по модели ОЕМ, в разработке собственных технологий и брендов, на продвижение новейших технологий и стимулирование исследований и разработок в традиционных отраслях экономики (субсидии на разработку новых продуктов, совместные исследования предприятий и на повышение уровня дизайна и эстетических характеристик продуктов). В 2014 г. бюджет данного направления программы составил 285 млн НТД [13. С. 186]. В 2009 г. в список задач программы было добавлено стимулирование модернизации МСП Тайваня посредством эффективного использования широких научно-исследовательских возможностей университетов и других 
исследовательских организаций с целью сделать университеты долгосрочными партнерами МСП в деле развития их ключевых технологий. Среди мероприятий данного направления основными являются консультации МСП с экспертами из университетов и исследовательских институтов о возможностях НИОКР для развития бизнеса, а также о возможностях участия в правительственных программах по поддержке НИОКР. К маю 2015 г. почти 10,5 тыс. МСП получили консультации от экспертов из более чем 140 тайваньских университетов и колледжей, также программа способствовала привлечению 5440 млн НТД частных инвестиций в МСП [2. С. 174].

7. В 2014 г. на смену Плану по содействию технологическому развитию сектора услуг была запущена сходная по целям и задачам Программа стимулирования инноваций и НИОКР в секторе услуг, ориентированная на поддержку внедрения новых видов услуг, новых деловых или маркетинговых моделей, а также новых торговых технологий. С 2014 по июнь 2015 г. по данной программе было одобрено 113 заявок, объем частных инвестиций, привлеченных благодаря программе, составил 130 млн НТД.

В последние несколько лет на Тайване все большее внимание уделяется созданию инновационных стартапов. 24 марта 2014 г. Национальный совет по развитию принял, а 19 августа того же года Исполнительный Юань Тайваня утвердил план по развитию инновационных стартапов «Удачный старт» [14] (創業拔萃). С сентября 2013 г. представители Национального совета по развитию проводили исследования местных и зарубежных условий для развития стартапов и пришли к выводу, что на Тайване еще только предстоит создать благоприятную среду для создания стартапов и молодежного предпринимательства, - на основе данных выводов и был принят план «Удачный старт».

Национальный совет по развитию выделил следующие сложности для создания на Тайване стартапов и предложил в Плане соответствующие методы их решения.

Во-первых, законодательная база не соответствует потребностям развития стартапов. Метод решения данной проблемы - снижение степени регламентации в области предпринимательства, что предполагает сбор информации о том, какие законодательные барьеры видят предприниматели на пути своей деятельности, а также изучение международного опыта регулирования в данной сфере и последующее приведение нормативных актов Тайваня в соответствие с данными потребностями и опытом.

Во-вторых, существует недостаток инвестиций на ранних этапах развития, который Национальный совет по развитию связывает с низкой привлекательностью такого рода инвестиций для местного и иностранного венчурного капитала. В качестве меры по решению этой проблемы правительством предлагаются: 1) содействие в установлении связей с иностранными инве- стиционными компаниями (например, сингапурскими), которые могут оказывать консультационные услуги по инвестированию в стартапы; 2) создание международных экспертных групп, которые могли бы выбирать перспективные тайваньские стартапы для совместного финансирования или получения иностранного венчурного капитала. В то же время этот механизм позволит привлечь большее внимание иностранных венчурных фондов к тайваньским стартапам.

В-третьих, наблюдаются недостаток международных связей - сложность привлечения зарубежных специалистов, капиталов и технологий - и - в то же время барьеры для выхода на международный рынок. Для преодоления данного ограничения предполагается создание в Тайбее стартап-кластера, аналогичного кластеру в Кремниевой долине или стартап-кластерам Tech City в Лондоне (создан в 2010 г.), Block71 в Сингапуре (создан в 2011 г.). Руководство тайваньским стартап-кластером планируется отдать в руки команде профессиональных менеджеров, работающих на частной основе. Строительство первой очереди данного кластера началось в 2014 г., строительство второй очереди было запланировано на 2016 г., окончание строительства намечено на 2018 г. Стоит отдельно отметить, что кластеры создают благоприятные условия для более активного использования аутсорсинга, в рамках которого снижается инвестиционная нагрузка на МСП с точки зрения оборудования и других активов, высвобождая средства для профильной деятельности [10. С. 149].

Программа «Удачный старт» должна быть выполнена в течение 5 лет (в 2014-2018 гг.), на ее реализацию на данный срок запланировано выделить 600 млн НТД бюджетных средств.

В качестве примера реализации политики по развитию международных связей МСП можно отметить сотрудничество с Японией. По мнению Министерства экономики Тайваня, продвижение сотрудничества с японскими МСП создало хорошие возможности для укрепления уже достаточно прочных связей между производственными и торговыми компаниями двух экономик. В конце 2011 г. стороны подписали тайваньско-японское соглашение о защите инвестиций, в янваpe 2012 г. Исполнительный Юань Тайваня одобрил План по налаживанию сотрудничества в области промышленности, в 2014 г. Управление по делам МСП инициировало план по сотрудничеству и обменам между тайваньскими и японскими МСП и созданию соответствующей платформы сотрудничества и обмена, которая должна способствовать дальнейшему укреплению связей в ключевых для обеих сторон отраслях (в том числе в области венчурного капитала). Кроме того, по мнению правительства острова, новые формы сотрудничества МСП двух сторон могут позволить совместно укреплять позиции на рынке материкового Китая [2. С. 190].

Среди результатов реализации упомянутых выше тайваньско-японских соглашений и планов по состоя- 
нию на 2014 г. можно назвать заключение 89 стратегических партнерств с потенциальным объемом деловых операций на сумму около 1,35 млрд НТД [2. С. 190].

Еще одна программа по содействию предпринимательству среди выпускников ВУЗов была начата в 2009 г. Министерством образования - программа «U-старт», которая призвана подготовить выпускников колледжей к предпринимательской деятельности посредством механизмов взаимодействия университетов и предприятий. По состоянию на апрель 2015 г. в рамках данной программы почти 600 стартапов получили субсидии Министерства образования, 330 из 600 проектов завершились созданием предприятий [15].

В программе «Удачный старт» в качестве одного из слабых мест стартапов назван недостаток инвестиций. И хотя проблема привлечения капитала делит пальму первенства с проблемой обеспеченности кадрами в списке сложностей малых и средних предприятий Тайваня, в последние 5 лет динамично развивается такой инструмент получения капитала, как краудфандинг ${ }^{4}$. Среди тайваньских краудфандинговых платформ наибольшей популярностью пользуются Flying $\mathrm{V}$, Zeczec, WeBackers, WeReport, Fuudai, DitFunding и HereO. Несмотря на то, что часто краудфандинг используется для привлечения средств и внимания к культурным проектам (например, начинающими музыкальными, художественными коллективами), на тайваньских платформах присутствуют и проекты, связанные с разработкой продуктов и применением технологий.

Помимо непосредственного привлечения капитала, краудфандинг выполняет функцию канала получения обратной связи от большого числа потенциальных потребителей и дает возможность оценить степень будущего принятия рынком нового продукта. Представляется, что данный инструмент может стать одним из полноценных способов создания высокотехнологичных стартапов на Тайване. Например, платформе FlyingV за первые 4 года своего существования (с 2012 по 2016 г.) удалось привлечь инвестиции в размере более $300 \mathrm{млн}$ НТД [16]. Для регулирования деятельности этого быстро развивающегося инструмента привлечения капитала Комитетом финансового надзора Исполнительного Юаня было принято решение разрешить краудфандинговым платформам, которые соответствуют определенным требованиям, заниматься так называемым акционерным краудфандингом - продажей акций частных микропредприятий большому числу микроинвесторов для привлечения капитала.

Влияние Рамочного соглашения об экономическом сотрудничестве на МСП Тайваня. Говоря о тенденциях развития тайваньских МСП в последние 5 лет, безусловно, нельзя оставить без внимания влияние на МСП такого важного документа, как Рамочное соглашение об экономическом сотрудничестве, заключенное 29 июня 2010 г. двумя сторонами Тайваньского пролива. Оставляя в стороне широко обсуждаемые возможные политические последствия Рамочного со- глашения, стоит рассмотреть его экономические результаты и влияние торговой и инвестиционной либерализации на малый и средний бизнес острова.

Тайваньские исследователи Ван Цзяньчуань, Линь Цзяхуэй и Цай Фэнхуан проанализировали положительные стороны и вызовы, которые заключает в себе Рамочное соглашение, с точки зрения малых и средних предприятий острова. К положительным последствиям реализации Рамочного соглашения ученые отнесли:

- расширение доступа на рынок сбыта на континенте, которое способствует росту ВВП острова, увеличению экспорта и импорта;

- упрощенное прохождение таможенных процедур при торговых операциях через Тайваньский пролив, ускорение логистики, что повышает эффективность работы МСП и позволяет им интегрироваться в цепочки поставок крупных предприятий;

- в таких отраслях, как финансы, строительство, недвижимость, морские перевозки, туризм, производство промышленных товаров, для МСП открываются новые возможности [17. С. 176].

В целом апологеты Рамочного соглашения полагают, что оно открыло для тайваньского бизнеса (в том числе малого и среднего) новые возможности по взаимодействию с материком, снизило риски и неопределенность данного взаимодействия, позволило глубже интегрироваться в производственную цепочку между двумя берегами Тайваньского пролива, а также не остаться в стороне от интеграционных процессов во всем Азиатском регионе.

Будучи одним из наиболее ярких результатов политического курса Ма Инцзю, президента от партии Гоминьдан в 2008-2016 гг., Рамочное соглашение не перестает быть темой ожесточенных межпартийных споров. Вероятно, именно неоднозначное отношение политиков и общественности к Рамочному соглашению не позволяет подвергать его критике в правительственных отчетах. В частности, в Белой книге по малым и средним предприятиям Тайваня от 2015 г., когда Гоминьдан еще оставался правящей партией, в то время как многие вопросы развития МСП рассмотрены достаточно самокритично (Книга издается Министерством экономики Тайваня), Рамочное соглашение содержит только положительные оценки. По данным Белой Книги, выгода от Рамочного соглашения с января 2011 г. по декабрь 2014 г. в виде экономии на таможенных платежах для тайваньских компаний достигла 2,2 млрд долл. США, половина от этих выгод приходится на долю малых и средних предприятий [2. С. 89].

Наиболее значимым негативным последствием реализации Рамочного соглашения является неблагоприятное воздействие на традиционные отрасли экономики: легкую промышленность, автомобилестроение, производство цемента, бытовой техники, стеклокерамики, которые были защищены протекционистскими барьерами, но после реализации соглашения столкнулись с возросшей конкуренцией со стороны предприя- 
тий континента [17. С. 176]. Профессор Тун Чжэньюань (Национальный Университет Чжэнчжи) указывает на снижение объема иностранных инвестиций на Тайвань и недостаточный рост в торговле по позициям, указанным в соглашении, который в 2011-2013 гг. был ниже, чем рост по товарным позициям, не указанным в нем [18]. В статье «Список ранних результатов три года спустя» [19], которая привлекла широкое международное внимание, также сделан вывод, что выгоды от Рамочного соглашения по результатам первых 3 лет отнюдь не соответствуют ожиданиям. В статье приводятся статистические данные, полученные «по специальным каналам», которые позволяют сделать вывод, что, несмотря на общий количественный рост товарооборота по позициям из данного списка ${ }^{5}$, компании с континента смогли увеличить долю в импорте Тайваня по всем своим 267 позициям из списка, тогда как доля тайваньских импортеров по 539 товарам из списка сократилась (при количественном росте).

В текстильной промышленности тайваньским предприятиям, имеющим сравнительно высокий уровень технологичности продукции, удалось расширить экспорт на материк, в то же время товары крупных предприятий с материка, поставляющих простые и существенно более дешевые текстильные изделия на остров, создают серьезную угрозу мелким предприятиям острова. Также происходит дальнейшее выхолащивание данной отрасли на острове: за первые три года после вступления в силу Рамочного соглашения объем производства текстильной промышленности упал на 40 млрд НТД, а количество работников отрасли снизилось на 5000 человек. Президент одной из крупнейших компаний-производителей функциональной ткани Everest Textile Роджер Е считает, что «единственный путь для текстильной промышленности Тайваня выжить в условиях данного соглашения повышать свою самодостаточность и изобретательность, активно развивать собственные бренды и продукты с особыми свойствами» [Там же]. В сфере машиностроения и производства инструментов ввиду агрессивного инвестирования материком в модернизацию своих предприятий тайваньский экспорт продукции данной отрасли на континент упал на 23\%, тогда как общее падение совокупного экспорта отрасли составило $18 \%$.

Ван Цзяньчуань, Линь Цзяхуэй и Цай Фэнхуан отмечают, что целью Управления по делам МСП после принятия Рамочного соглашения стало стимулирование развития кооперации между МСП (кластерного эффекта), а также развитие инновационных услуг с высокой добавленной стоимостью, которые создадут экономию, обусловленную расширением сфер деятельности [17. С. 178]. Однако еще в 2008 г. началась реализация плана по продвижению развития комплексных инновационных услуг малых и средних предприятий, нацеленного на интеграцию взаимодополняющих МСП, занимающихся технологическими исследованиями и разработками, прикладными технологиями, ком- мерциализацией, организацией сбыта, для создания кластерной сети обслуживания, позволяющей производить обмен информацией и создавать новые возможности для бизнеса и тем самым повышать конкурентоспособность тайваньских МСП [20]. По данным министерства экономики Тайваня, к концу 2010 г. в рамках этой программы было сформировано 45 объединений и при сотрудничестве 821 предприятия было создано 36 инновационных товаров и услуг [21]. Согласно отчету УМСП, в 2014 г. результаты работы по данному направлению включают содействие в создании 11 инновационных МСП-кластеров, включающих 185 малых и средних предприятий, занимающихся инновациями в области технологий, услуг и бизнес-моделей, содействие в создании 21 образцового предприятия [2. С. 168-169].

Таким образом, последние пять лет принесли малым и средним предприятиям Тайваня новые вызовы, связанные со снижением темпов роста мировой экономики и повышением конкуренции из-за стремительного развития электронной коммерции, которая разрушает барьеры для выхода на мировые рынки. В то же время она же создает новые возможности для малых и средних предприятий. Правительство острова все большее внимание уделяет развитию стартапов, повышению сервисной составляющей товаров и технологического уровня услуг. При этом сохраняется взятый более 15 лет назад курс на необходимость развития собственных инноваций. Однако необходимо отметить, что помимо традиционного инструмента частичного субсидирования НИОКР малых и средних предприятий - в 2010-х гг. в правительственных программах все больший акцент делается на нефинансовое стимулирование, меры, ориентированные на совершенствование инновационной среды: информационную поддержку, стимулирование достижения кластерного эффекта за счет взаимодействия МСП и исследовательских организаций и вузов.

Несмотря на серьезность вызовов, стоящих перед его экономической системой, на 97\% состоящей из малых и средних предприятий, Тайвань сохраняет высокие позиции в мировом рейтинге конкурентоспособности - в 2015-2016 гг. остров занял 15-е место [22], в мировом рейтинге предпринимательства 2016 г. ${ }^{6}$ - 6-е место [23], в рейтинге инновационной конкурентоспособности - 10-е место (2014-2015 гг.) [24]. Эти показатели свидетельствуют о том, что Тайваню и, в частности, гоминьдановскому правительству в последние годы удавалось адаптироваться к меняющимся условиям и корректировать экономический курс, чтобы обеспечивать стабильные темпы роста экономики. Избранная в январе 2016 г. президент Цай Инвэнь одними из основных своих задач считает необходимость снижения экономической зависимости от рынка континентального Китая и поиск новых драйверов экономического роста. Несомненно, любые повороты в этой области отразятся на секторе малого и среднего бизнеса. 


\title{
ПРИМЕЧАНИЯ
}

\begin{abstract}
1 新南向政策. Этот курс назван новым, так как во второй половине 1990-х гг. тогдашний президент Ли Дэнхуэй предостерегал тайваньских предпринимателей от сближения с материковым Китаем, призывая «идти на юг». Новая южная политика предполагает акцент на развитие экономических, технологических и торговых связей прежде всего со странами АСЕАН и Индией. Повышение уровня заработной платы на материковой части Китая, активизация политики по снижению уровня загрязнения окружающей среды, запрет на размещение «грязных» производств на территории континента - все это обусловливает повышенное внимание к странам АСЕАН.

2 «Интернет вещей» - концепция объединения вещей (преимущественно электронной техники) через коммуникационную сеть для взаимодействия между собой, а также со внешней средой.

${ }^{3}$ Под нематериальным производством подразумевается производство продуктов и услуг, не имеющих материальной формы, например программное обеспечение, образовательные услуги, здравоохранение, дизайнерские и конструкторские разработки и т.д.

${ }^{4}$ Краудфандинг - механизм привлечения финансирования от широких масс с целью реализации какого-либо проекта, коллективное финансирование, которое, как правило, осуществляется через Интернет.

${ }^{5}$ Соглашение предусматривает снижение торговых барьеров для импорта 267 товарных позиций на Тайвань и импорта 539 товарных позиций на материк.

${ }^{6}$ Данный рейтинг составляется на основе таких показателей, как отношение, способность и стремление местного населения к предпринимательству, а также социальная и экономическая инфраструктура ведения бизнеса.
\end{abstract}

\section{ЛИТЕРАТУРА}

1. Standards for Identifying Small and Medium Enterprises. Small and Medium Enterprise Administration, Ministry of Economic Affairs of Taiwan. 2015. URL: http://www.moeasmea.gov.tw/ct.asp?xItem=8261\&CtNode=530\&mp=2 (дата обращения: 12.02.2017).

2. White Paper on Small and Medium Enterprises in Taiwan 2015. Small and Medium Enterprise Administration, Ministry of Economic Affairs, Taiwan. October 2015. 244 p.

3. Manpower Survey data, 2013-2014. Directorate-General of Budget, Accounting and Statistics, Executive Yuan, Taiwan. URL: http://eng.dgbas.gov.tw/mp.asp?mp=2 (дата обращения: 12.02.2017).

4. VAT data, 2010-2014. Fiscal Information Agency, Ministry of Finance, Taiwan. URL: http://www.fia.gov.tw/dp.asp?mp=5 (дата обpaщения: 12.02.2017)

5. Taiwan Statistical Data Book 2015. National Development Council. Taiwan, 2015. 369 p.

6. Цзючжи яньшуо [Инаугурационная речь президента Тайваня]. Чжунхуа миньго цзунтунфу. 2016. URL: http://www.president.gov.tw/Default.aspx? tabid=1565 (дата обращения: 12.02.2017).

7. Цай Инвэнь фабяо люйнэн кэцзи чуансинь чанье чжицы чуаньвэнь [Цай Инвэнь опубликовала полный текст речи о научно-технологической инновационной отрасли - «зеленой» энергетике]. Миньчжу цзиньбу дан. 18.09.2015. URL: http://www.dpp.org.tw/news_content.php?kw $=\& \mathrm{~m} 1=11 \& \mathrm{y} 1=2016 \&$ menu_sn $=\&$ sub_menu $=43 \&$ show_title $=\&$ one_page $=10 \&$ page $=1 \&$ start_p $=1 \&$ act $=\&$ sn $=8191 \&$ stat $=\&$ order_type $=$ desc\&order_col=add_date\&data_type=, свободный (дата обращения: 12.02.2017).

8. "Asian Silicon Valley" plan to transform economic structure. Department of Information Services, Executive Yuan, Taiwan. 08.09.2016. URL: http://www.ey.gov.tw/en/News_Content2.aspx?n=1C6028CA080A27B3\&sms=E0588283EFAA02AD\&s=B589702ACC066386 (дата обращения: 12.02.2017).

9. Тайвань чанье цзего уюхуа - санье сыхуа синтун цзихуа [Оптимизация структуры тайваньского производства - план «Четыре реформы трех отраслей»]. Синчжэнюань. 02.10.2012. 76 с.

10. Хуан Жуйжун. Тайвань чжунсяо цие фуцянь сомяньлиньдэ вэньтичжи яньцзю - и дяньцзы чанье вэйли [Исследование проблем малых и средних предприятий Тайваня на примере электронной промышленности] // Чжунхуа цзишу сюэюань сюэбао. 2003. № 27. С. $141-157$.

11. Taiwan-proposed O2O Initiative wraps up at APEC meeting // Taiwan Today. 10.09.2016. URL: http:/taiwantoday.tw/ ct.asp?xItem=247843\&ctNode=2175 (дата обращения: 12.02.2017).

12. R\&D Expenditures by the Number of Employees. National Science and Technology Survey - Statistic Query. Ministry of Science and Technology, Taiwan. 2016. URL: https://ap0512.most.gov.tw/WAS2/English/AsTechnologyEStatistics.aspx?ID=17 (дата обращения: 12.02.2017).

13. White Paper on Small and Medium Enterprises in Taiwan 2014. Small and Medium Enterprise Administration, Ministry of Economic Affairs, Taiwan. October 2014. 258 p.

14. Headstart Project (Approved Version). National Development Council, Taiwan. August 2014. 25 p.

15. U-start. Youth Development Administration, Ministry of Education, Taiwan. URL: http://ustart.moe.еdu.tw/ (дата обращения: 12.02.2017).

16. Гуаньюй вомэнь [O нас]. FlyingV. URL: https://www.flyingv.cc/about (дата обращения: 12.02.2017).

17. Ван Цзяньчуань, Линь Цзяхуэй, Цай Фэнхуан. ЕCFА дуй чжунсяо цие дэ инсян, фудао цзыюань цзешао цзи чжэнцэ цзяньи [Влияние ЕСFА на малые и средние предприятия, направляемые ресурсы и рекомендации в отношении политического курса] // Чжунсяо цие фачжань цзикань. 2010. № 15. С. 173-181.

18. Tong Zhen-yuan. ECFA bringing only limited benefits // Taipei Times. 19.05.2013. URL: http://www.taipeitimes.com/News/editorials/archives/ 2013/05/19/2003562618/1 (дата обращения: 12.02.2017).

19. Chang Hsiang-yi. Demystifying ECFA. The Yearly Harvest List, 3 Years on // The commonwealth Magazine. 02.05.2014. URL: http://english.cw.com.tw/article.do?action=show\&id=14757 (дата обращения: 12.02.2017).

20. Чжунсяо цие цюньцзю чуансинь чжэнхэ фуу [Инновационные комплексные услуги объединений малых и средних предприятий]. Цзинцзибу чжунсяо цие чу. URL: http://www.moea.gov.tw/AD/Ad02/content/ContentDetail.aspx?menu_id=3972 (дата обращения: 12.02.2017).

21. Цюньцзю чуансинь - дяньши чэнцзинь «2010 чжунсяо цие цюньцзю чуансинь чжэнхэсин фуу цзихуа» чэнгочжань цзи гоцзи луньтань [Инновационные объединения - результаты «Плана по развитию инновационных комплексных услуг объединений малых и средних предприятий 2010 г.» и их представление на международных форумах] // Цзинцзибу чжунсяо цие чу. URL: http://www.moeasmea. gov.tw/ct.asp?xItem=9032\&ctNode=724\&mp=3 (дата обращения: 12.02.2017).

22. GCI Global Competitiveness Index. World Economic Forum. 2016. URL: http://reports.weforum.org/global-competitiveness-report-20152016/competitiveness-rankings/ (дата обращения: 12.02.2017).

23. Global Entrepreneurship Index. The Global Entrepreneurship and Development Institute. 2016. URL: https:/thegedi.org/global-entrepreneurshipand-development-index/ (дата обращения: 12.02.2017).

24. Global Competitiveness Report 2014-2015. World Economic Forum. 2015. URL: http://reports.weforum.org/global-competitivenessreport-20142015/wp-content/blogs.dir/54/mp/files/pages/files/tables3-7-wef-globalcompetitivenessreport-2014-15-2.pdf (дата обращения: 12.02.2017). 
Keywords: Taiwan; small and medium-sized enterprises; innovations.

Small and medium-sized enterprises (SMEs) amount to $97,6 \%$ of the total number of enterprises in Taiwan and provide $78 \%$ of the total employment in the island. Substantial changes in regional and global economic environment imply new challenges for SMEs and make it more difficult for the Taiwanese government to develop SMEs. Therefore, the purpose of this research is to study the experience of Taiwan in the sphere of SMEs development stimulation under conditions which evolved after the world financial crisis of 2008-2009.

Unfavorable conditions for the SMEs development mainly include 1) the increase of science and technology level of Mainland China economy and its active export-facilitating policy as well as the world economy and world trade growth rate decrease, what tends to be a considerable threat for the Taiwanese export-oriented economy. Besides, wide spread of e-commerce which basically eliminate the borders between economies together with fast reduction of technologies' life-cycle makes global competition as strong as never before. Nevertheless, both Ma Ying-jeou and Tsai Ing-wen administrations defined small and medium-sized enterprises as one of the major sources of future economic development.

In 2016, Tsai Ing-wen administration officially recognized that the OEM model of contract manufacturing which was widely used by Taiwanese enterprises become outdated and can no longer be an economic driver for Taiwan. According to the Taiwanese government's view, the future sources of economic development will include innovations, servitization and products' specificity enhancement. Another important policy implies creation of favorable conditions (so-called "ecosystem") for start-ups which embody innovation ideas and often have goods prospects in terms of commercialization.

The government of Taiwan carries out several SMEs support programs including research and development subsidizing, it facilitates new information technologies and e-commerce instruments implementation, supports the leading enterprises and their products which have great potential. It's worth noting that in recent years the instruments of supporting SMEs applied by the government have transformed: the measures of direct subsidizing have been diminishing, and, simultaneously, the measures of providing favorable environment for establishing new enterprises and effective operation of the existing SMEs and non-financial support (technical assistance and consultation) have expanded.

The Economic Cooperation Framework Agreement signed by the two sides of the Taiwan Strait in 2010 led to controversial consequences for the Taiwanese SMEs. On the one hand, it expanded the access of Taiwanese SMEs to the mainland market and reduced customs expenditures of Taiwanese exporting companies. On the other hand, the Agreement allowed mainland business to foster its penetration into the island's market and further reduced competitiveness of Taiwanese traditional industries.

\section{REFERENCES}

1. Ministry of Economic Affairs of Taiwan. (2015a) Standards for Identifying Small and Medium Enterprises. Small and Medium Enterprise Administration, Ministry of Economic Affairs of Taiwan. [Online] Available from: http://www.moeasmea.gov.tw/ct.asp?xItem=8261\&CtNode=530\&mp=2. (Accessed: 12th February 2017).

2. Ministry of Economic Affairs of Taiwan. (2015b) White Paper on Small and Medium Enterprises in Taiwan 2015. Small and Medium Enterprise Administration, Ministry of Economic Affairs, Taiwan. October 2015. [s.1., s.n.].

3. Directorate-General of Budget, Accounting and Statistics, Executive Yuan, Taiwan. (n.d.) Manpower Survey data, 2013-2014. [Online] Available from: http://eng.dgbas.gov.tw/mp.asp? $\mathrm{mp}=2$. (Accessed: 12th February 2017).

4. Ministry of Finance, Taiwan. (n.d.) VAT data, 2010-2014. Fiscal Information Agency, Ministry of Finance, Taiwan. [Online] Available from: http://www.fia.gov.tw/dp.asp?mp=5. (Accessed: 12th February 2017).

5. National Development Council, Taiwan. (2015) Taiwan Statistical Data Book 2015. [s.1., s.n.].

6. Office of the President, Republic of China (Taiwan). (2016) Tszyuchzhi yan'shuo [Inauguration speech of the President of Taiwan]. [Online] Available from: http://www.president.gov.tw/Default.aspx?tabid=1565. (Accessed: 12th February 2017).

7. Office of the President, Republic of China (Taiwan). (2015) Tsay Inven' fabyao lyuynen ketszi chuansin' chan'ye chzhitsy chuan'ven' [Tsai Inven published the full text of the speech on the scientific and technological innovation branch - "green" energy]. Min'chzhu tszin'bu dan. 18th September. [Online] Available from: http://www.dpp.org.tw/news_content.php?kw=\&m1 $=11 \& y 1=2016 \& m e n u \_s n=\& s u b \_m e n u=43 \&$ show title= \&one_page $=10 \&$ page $=1 \&$ start_p $=1 \&$ act $=\& \mathrm{sn}=8191 \&$ stat $=\&$ order_type $=$ desc\&order_col=add_date\&data_type $=$. (Accessed: 12 th February 2017 ).

8. Executive Yuan, Taiwan. (2016) “Asian Silicon Valley" plan to transform economic structure. 8th September. [Online] Available from: http://www.ey.gov.tw/en/News_Content2.aspx?n=1C6028CA080A27B3\&sms=E0588283EFAA02AD\&s=B589702ACC066386. (Accessed: 12th February 2017).

9. Taiwan. (2012) Tayvan' chan'ye tszego uyukhua - san'ye sykhua sintun tszikhua [Optimization of the structure of Taiwanese production - the plan "Four reforms of three industries"]. Sinchzhenyuan'. 2nd October.

10. Taiwan. (2003) Khuan Zhuyzhun. Tayvan' chzhunsyao tsiye futsyan' somyan'lin'de ven'tichzhi yan'tszyu - i dyan'tszy chan'ye veyli [Study of the problems of Taiwan's small and medium-sized enterprises on the example of the electronics industry]. Chzhunkhua tszishu syueyuan' syuebao. 27. pp. $141-157$.

11. Taiwan Today. (2016) Taiwan-proposed O2O Initiative wraps up at APEC meeting. 10th September. [Online] Available from: http://taiwantoday.tw/ct.asp?xItem=247843\&ctNode=2175. (Accessed: 12th February 2017).

12. Ministry of Science and Technology, Taiwan. (2016) R\&D Expenditures by the Number of Employees. National Science and Technology Survey Statistic Query. [Online] Available from: https://ap0512.most.gov.tw/WAS2/English/AsTechnologyEStatistics.aspx?ID=17. (Accessed: 12th February 2017).

13. Ministry of Economic Affairs, Taiwan. (2014) White Paper on Small and Medium Enterprises in Taiwan 2014. Small and Medium Enterprise Administration, Ministry of Economic Affairs, Taiwan. October 2014. [s.1., s.n.].

14. National Development Council, Taiwan. (2014) Headstart Project (Approved Version). August 2014. [s.1., s.n.].

15. Ministry of Education, Taiwan. (n.d.) U-start. Youth Development Administration, Ministry of Education, Taiwan. [Online] Available from: http://ustart.moe.edu.tw/. (Accessed: 12th February 2017).

16. FlyingV. (n.d) Guan'yuy vomen' [About Us]. [Online] Available from: https://www.flyingv.cc/about. (Accessed: 12th February 2017).

17. Wang Jianchuan, Lin Jiahei, Tsai Fenghuang. (2010) ECFA duy chzhunsyao tsiye de insyan, fudao tszyyuan' tszeshao tszi chzhentse tszyan'i [Influence of ECFA on small and medium-sized enterprises, directed resources and policy recommendations]. Chzhunsyao tsiye fachzhan' tszikan'. 15. pp. $173-181$.

18. Tong Zhen-yuan. (2013) ECFA bringing only limited benefits. Taipei Times. 19th May. [Online] Available from: http://www.taipeitimes.com/News/editorials/archives/2013/05/19/2003562618/1. (Accessed: 12th February 2017).

19. Chang Hsiang-yi. (2014) Demystifying ECFA. The Yearly Harvest List, 3 Years on. The Commonwealth Magazine. 2nd May. [Online] Available from: http://english.cw.com.tw/article.do?action=show\&id=14757. (Accessed: 12th February 2017).

20. Ministry of Economic Affairs, ROC. (n.d.) Chzhunsyao tsiye tsyun'tszyu chuansin' chzhenkhe fuu [Innovative integrated services of associations of small and medium enterprises]. [Online] Available from: http://www.moea.gov.tw/AD/Ad02/content/ContentDetail.aspx?menu_id=3972. (Accessed: 12th February 2017). 
21. Ministry of Economic Affairs, ROC. (n.d.) Tsyun'tszyu chuansin'-dyan'shi chentszin' "2010 chzhunsyao tsiye tsyun'tszyu chuansin' chzhenkhesin fuu tszikhua" chengochzhan' tszi gotszi lun'tan' [Innovative association - the results of the "Plan for the development of innovative integrated services of small and medium enterprises in 2010" and their representation in international forums]. [Online] Available from: http://www.moeasmea.gov.tw/ct.asp?xItem=9032\&ctNode=724\&mp=3. (Accessed: 12th February 2017).

22. World Economic Forum. (2016) GCI Global Competitiveness Index. [Online] Available from: http://reports.weforum.org/global-competitivenessreport-2015-2016/competitiveness-rankings/. (Accessed: 12th February 2017).

23. The Global Entrepreneurship and Development Institute. (2016) Global Entrepreneurship Index. [Online] Available from: https:/thegedi.org/globalentrepreneurship-and-development-index/. (Accessed: 12th February 2017).

24. World Economic Forum. (2015) Global Competitiveness Report 2014-2015. [Online] Available from: http://reports.weforum.org/globalcompetitivenessreport-2014-2015/wp-content/blogs.dir/54/mp/files/pages/files/tables3-7-wef-globalcompetitivenessreport-2014-15-2.pdf. (Accessed: 12th February 2017). 